\title{
A dietary sterol trade off determines lifespan responses to dietary restriction in Drosophila melanogaster
}

Brooke Zanco, Christen K. Mirth, Carla M. Sgrò, Matthew D.W. Piper*

Monash university, School of Biological Sciences, Clayton, 3800, Australia

* Correspondence: matthew.piper@monash.edu 


\section{Abstract}

2

3 Diet plays a significant role in maintaining lifelong health. In particular, lowering the dietary

4 protein : carbohydrate ratio can improve lifespan. This has been interpreted as a direct

5 effect of these macronutrients on physiology. Using Drosophila melanogaster, we show that

6 the role of protein and carbohydrate on lifespan is indirect, acting by altering the

7 partitioning of limiting amounts of dietary sterols between reproduction and lifespan.

8 Shorter lifespans in flies fed on high protein : carbohydrate diets can be rescued by

9 supplementing their food with cholesterol. Not only does this fundamentally alter the way

10 we interpret the mechanisms of lifespan extension by dietary restriction, these data

11 highlight the important principle that life histories can be affected by nutrient-dependent

12 trade-offs that are indirect and independent of the nutrients (often macronutrients) that are

13 the focus of study. This brings us closer to understanding the mechanistic basis of dietary

14 restriction. 


\section{Introduction}

17 Dietary restriction, also called calorie restriction, is a moderate reduction in food intake that extends healthy lifespan across a broad range of taxa, from yeast to primates (Chapman \& Partridge, 1996; Colman et al., 2009; Lin et al., 2002; McCay et al., 1935). The generality of this observation has inspired confidence that the health benefits of dietary restriction might also be employed to improve human ageing (Campisi et al., 2019). In an attempt to harness its benefits, a great deal of current research is focused on discovering the nutritional components and the molecular mechanisms that underpin the lifespan benefits of dietary restriction (López-otín et al., 2013; Simpson et al., 2017).

Our current understanding of how diet modifies lifespan has grown out of evolutionary theory and experiments using model organisms. The most prominent theoretical explanation has been the disposable soma theory, which employs resource-based trade-offs to explain how dietary restriction can benefit lifespan (Kirkwood, 1977; Shanley \& Kirkwood, 2000). This theory postulates that organisms will maximise fitness by strategically partitioning limiting dietary energy either to reproduction or somatic maintenance, the latter determining lifespan. This means that longer lifespan is inevitably coupled with reduced reproduction because both traits compete for the same limiting resource.

Recent experimental work across a broad range of taxa has challenged the disposable soma theory by demonstrating that reproduction and lifespan respond predominantly to the balance of dietary macronutrients, not the overall energy content of the diet (Mair et al., 2005; Lee et al., 2008; Skorupa et al., 2008; Grandison et al., 2009; Solon-Biet et al., 2014; Solon-Biet et al., 2015; Simpson et al., 2017; Regan et al., 2020). Specifically, high protein, low carbohydrate diets are consistently associated with high reproduction and short lifespan, while low protein, high carbohydrate diets are associated with longer lifespan and lower levels of reproduction (Piper et al., 2011; Simpson et al., 2017). These data indicate that lifespan and reproduction are not in competition for limiting energy derived from the diet, but instead are optimised at different dietary protein : carbohydrate ratios. In response to these findings, an enormous effort is now focused on uncovering how macronutrient rebalancing, in particular protein dilution, acts to improve lifespan (Blagosklonny, 2006, 
2010; Moatt et al., 2020; Regan et al., 2020; Speakman, 2020). Accumulating evidence indicates that the effect is mediated by reducing signalling through the amino acid sensitive Target Of Rapamycin (TOR) pathway to enhance cellular proteostasis (Sanz et al., 2004; Ayala et al., 2007; Raubenheimer \& Simpson, 2009; Simpson \& Raubenheimer, 2009; Taylor \& Dillin, 2011; Fansonet et al, 2012; Sabatini, 2017).

Although detrimental for lifespan, relatively high protein, low carbohydrate diets are beneficial for female reproduction (Chong et al., 2004; Solon-Biet., et al., 2015). We have studied this closely in the fruitfly Drosophila melanogaster, where the principle driver of egg production is dietary protein (Min \&Tatar, 2006; Grandison et al., 2009; Piper et al., 2017). Although protein is key, females must transfer dozens of nutrients into eggs for future embryo formation and not all of these components contribute to the flies' decision to produce eggs ( Piper et al., 2014; Mirth et al., 2019; Wu et al., 2020). This means that high protein diets might drive mothers to produce eggs at a faster rate than they can support if the diet contains insufficient levels of the other components that are required to make eggs. In this scenario, the macronutrients would have an indirect effect on lifespan by changing the availability of another limiting nutrient for somatic maintenance. If true, this would move the focus of mechanistic studies away from the direct effects of protein, TOR and proteostasis, towards some other component of nutritional physiology. Distinguishing between these possible causes of death is important since it would fundamentally change our understanding of the way diet alters lifespan. It also has the important knock-on effect that we could change the way we design diets for longer life. For instance, supplementing high protein diets with key limiting nutrients would be as beneficial as restricting dietary protein or treating with pharmacological suppressors of TOR.

Of the many studies that have examined the effects of dietary protein and carbohydrate on lifespan and reproduction in Drosophila, most have done so by varying dietary yeast and sugar proportions, where yeast is the flies' natural source of protein (Mair et al., 2005; Lee et al., 2008; Skorupa et al., 2008). However, yeast also contains all of the fly's other essential macro and micronutrients whose relative proportions can change, and thus possibly interact with protein and carbohydrates to dictate life history outcomes. We have 
79 micronutrient for insects, imposes a minor cost on reproduction, but a substantial (>50\%)

80 cost to lifespan (Piper et al., 2014; Wu et al., 2020). These data indicate that yeast sterol

81 levels may contribute to the effects on lifespan of protein and carbohydrate. To investigate

82 the interactions between dietary protein, carbohydrate, and sterols systematically, we have

83 used the design principles of the geometric framework for nutrition (Simpson \&

84 Raubenheimer, 2012; Simpson \& Raubenheimer, 1993) and a completely defined (holidic)

85 diet that allows us to control the levels of each nutrient independently of all others (Piper et

86 al., 2014; Piper et al., 2017). These data point to an important role for sterols in determining

87 Drosophila lifespan, which we verified to be relevant in two yeast based media that are

88 often used in Drosophila lifespan studies. This work is critical to identifying how diet

89 modifies lifespan at the molecular level, and highlights a new way to think about diet design

90 to improve healthy ageing. 
Results:

Protein: carbohydrate ratio influences lifespan and reproduction

To examine the interactive effects of dietary protein, carbohydrate, and cholesterol on Drosophila lifespan and fecundity, we used our completely defined (holidic) diet (Piper et al., 2014) to manipulate each nutrient independently of all others. We selected dietary protein and carbohydrate concentrations that we know to elicit the full range of lifespan and fecundity responses to dietary restriction (Lee et al., 2008; Piper et al., 2014, 2017; Ma et al., 2020).

Similar to what we and others have found previously (Mair et al., 2005; Lee et al., 2008; reproduction were modified by dietary protein manipulations (Figure 1). Specifically, egg production showed a linear, positive correlation with dietary protein content (Supplementary table 3), while lifespan showed a peak at intermediate protein (67 d median at $10.7 \mathrm{~g} / \mathrm{l})$, and fell away at both higher ( $48 \mathrm{~d}$ median at $33.1 \mathrm{~g} / \mathrm{l}$ ) and lower ( $43 \mathrm{~d}$ median at $5.2 \mathrm{~g} / \mathrm{l}$ ) concentrations (Figure $1 \mathrm{a}-\mathrm{b}$; Supplementary Table 4). Thus, as is typical for dietary restriction experiments, restricting dietary protein from high to intermediate levels increased lifespan and decreased reproduction (Lee et al., 2008; Skorupa et al., 2008; Grandison et al., 2009; Katewa et al., 2016; Le Couteur et al., 2016).

113 When increasing dietary carbohydrate against an otherwise fixed nutritional background, egg laying was suppressed in a dose-dependent fashion, but lifespan remained at its maximum level and was unchanged across all carbohydrate doses ( $66 \mathrm{~d}$ median, Figure $1 \mathrm{c}-$

116 d). The diet with the lowest concentration of carbohydrate $(5.7 \mathrm{~g} / \mathrm{l})$, which also contained

117 the intermediate protein level $(10.7 \mathrm{~g} / \mathrm{l})$, supported both maximum lifespan (Figure $1 \mathrm{~d} ; 67 \mathrm{~d}$

118 median) and the highest level of egg laying (75 eggs/female) of any diet in our experiment.

119 Thus, as we have previously shown ( Piper et al., 2017), balancing the dietary protein and

120 carbohydrate concentrations can reveal a single dietary optimum for both traits, showing that lifespan shortening is not necessarily caused by high egg laying alone. 
a)

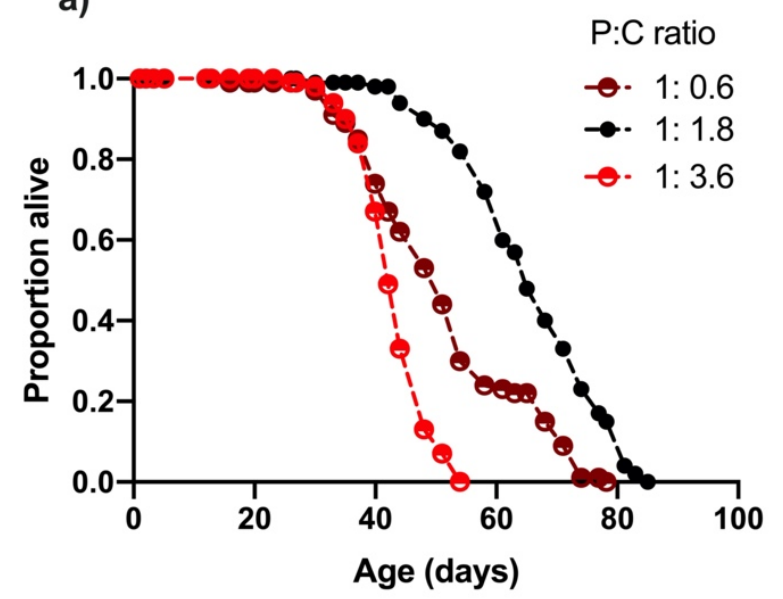

c)

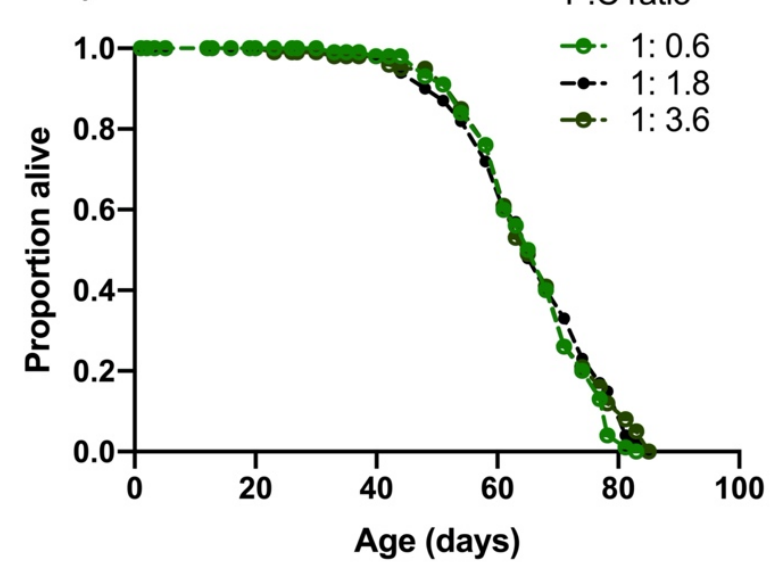

b)

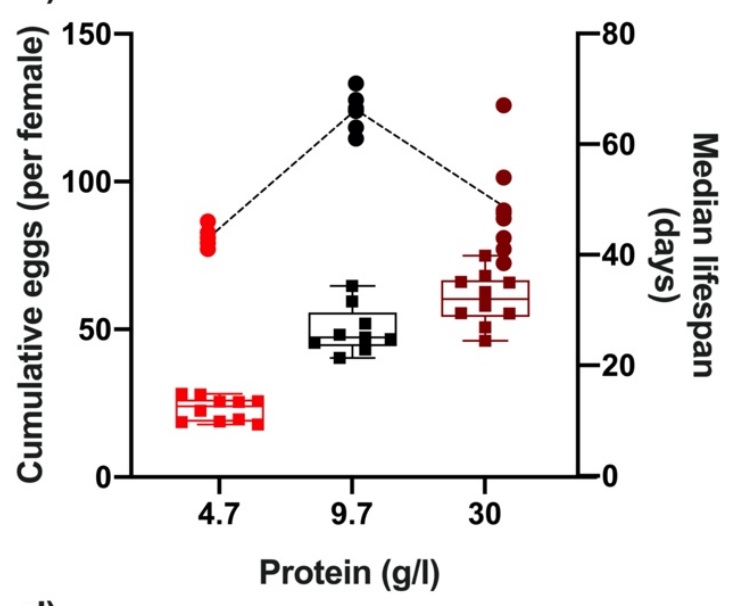

d)

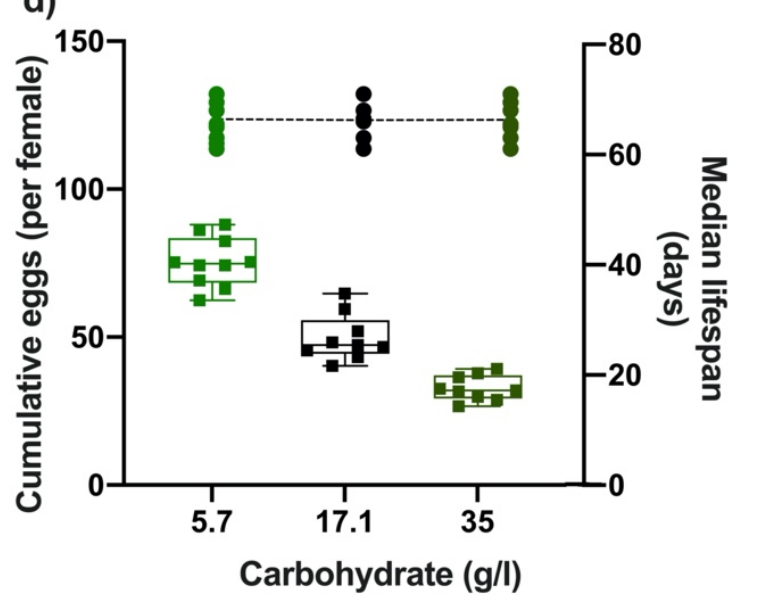

125 Figure 1. Changing dietary protein and carbohydrate concentrations modify Drosophila

126 lifespan and fecundity. (a, b) Lifespan was maximised at our intermediate dose of dietary

127 protein (carbohydrate fixed at $17.1 \mathrm{~g} / \mathrm{l}$ ) but was unaffected by our carbohydrate $(\mathrm{c}, \mathrm{d}$ )

128 concentration range (protein fixed at $10.7 \mathrm{~g} / \mathrm{l}$ ). (b) Cumulative egg production had a

129 significant positive relationship with protein levels and (d) significant negative correlation

130 with dietary carbohydrate content. Note that the intermediate protein and carbohydrate

131 diet (10.7g/I protein, $17.1 \mathrm{~g} / \mathrm{l}$ carbohydrate) is common to both nutrient dilution series. The

132 median survival data in panels (b) and (d) represent data from replicates that are combined

133 in panels (a) and (c) respectively. Statistical analyses reported in Supplementary Table 3 and

134 Supplementary Table 4. 
138 Most dietary restriction studies on Drosophila vary dietary protein by modifying the yeast 139 levels in food (Chapman \& Partridge, 1996; Mair et al., 2005; Lee et al., 2008; Skorupa et al., 140 2008). While yeast is the flies' major source of protein, it is also their only source of dozens 141 of other nutrients, including sterols, which are essential micronutrients for insects (Carvalho 142 et al., 2010). To quantify the effects of varying dietary sterol levels on fly lifespan and egg

143 laying, we maintained flies on the same set of diets as above, varying in protein and

144 carbohydrate concentrations, while also varying cholesterol across four different levels: 0 $\mathrm{g} / \mathrm{l}, 0.15 \mathrm{~g} / \mathrm{l}$ (low), $0.3 \mathrm{~g} / \mathrm{l}$ (medium; also our standard level) and $0.6 \mathrm{~g} / \mathrm{l}$ (high).

We first compared the flies' responses to variation in both protein and cholesterol (Figure 2). In general, lifespan was optimised at our intermediate dose of protein, while increasing cholesterol was beneficial, but with diminishing effects as its concentration was increased (Supplementary Figure $1 \mathrm{a}-\mathrm{b}$ and Supplementary Table 5). Interestingly, changing cholesterol modified the flies' lifespan response to protein, an effect that can be seen when the data are separated by level of cholesterol addition (Figure 2). At $0 \mathrm{~g} / \mathrm{l}$ cholesterol (Figure 2a) increasing protein concentration in the diet decreased lifespan. However, at $0.15 \mathrm{~g} / \mathrm{l}$ cholesterol, the shape of the response changed such that only the highest protein concentration decreased lifespan (35d median; Figure 2b) when compared with intermediate $(9.7 \mathrm{~g} / \mathrm{l} ; 55 \mathrm{~d}$ median) and low protein $(4.7 \mathrm{~g} / \mathrm{l} ; 52 \mathrm{~d}$ median) diets. At $0.3 \mathrm{~g} / \mathrm{l}$ of cholesterol, lifespan was highest on the diet with intermediate protein concentration (66d median) and flies on the high protein diet were longer lived (49d median) than the flies on the lowest protein diet (43d median). Finally, increasing cholesterol from $0.3 \mathrm{~g} / \mathrm{l}$ to $0.6 \mathrm{~g} / \mathrm{l}$

160 (Figure 2d) did not change the way that lifespan responded to protein. Thus, lowering dietary cholesterol was detrimental for lifespan and it intensified the negative effects of increasing dietary protein concentrations.

164 Across the same set of diets, we observed a generally beneficial effect on egg laying of 165 increasing dietary protein and cholesterol, and both had diminishing benefits as their concentrations increased (Supplementary Figure $1 \mathrm{~d}$-e; Supplementary Table 6). Cholesterol also modified the way egg laying was affected by dietary protein (Figure 2). Increasing 
168 cholesterol from 0g/l (Figure 2a) to $0.15 \mathrm{~g} / \mathrm{l}$ (Figure 2b) amplified the positive effect on egg

169 laying of increasing dietary protein. Further increasing cholesterol to $0.3 \mathrm{~g} / \mathrm{l}$ had an

170 additional benefit for egg laying (Figure 2c), but only for flies on the highest protein diet

171 (compare Figure $2 \mathrm{~b}$ with Figure $2 \mathrm{c}$ ), while increasing cholesterol even further, to $0.6 \mathrm{~g} / \mathrm{l}$

172 (Figure $2 \mathrm{~d}$ ), did not change egg laying from that seen on $0.3 \mathrm{~g} / \mathrm{l}$. Thus, the response of egg

173 laying to increasing protein was only compromised when cholesterol was completely

174 removed from the diet, or when cholesterol was low $(0.15 \mathrm{~g} / \mathrm{l})$ and protein was high $(30 \mathrm{~g} / \mathrm{l})$

175 (Figure $2 b$ ).

176

177 Together, these data show that reducing cholesterol had negative effects on both lifespan

178 and egg laying, and that these negative effects became more pronounced with increasing

179 dietary protein. Furthermore, the negative interaction between lowering cholesterol and

180 increasing protein was more severe and occurred at a lower protein concentration for

181 lifespan than it did for egg laying.

182

183 
Cholesterol (g/l)

a)

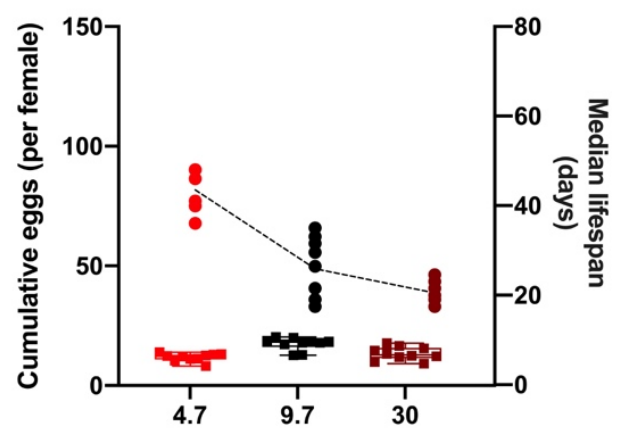

Cholesterol (g/l)

c)

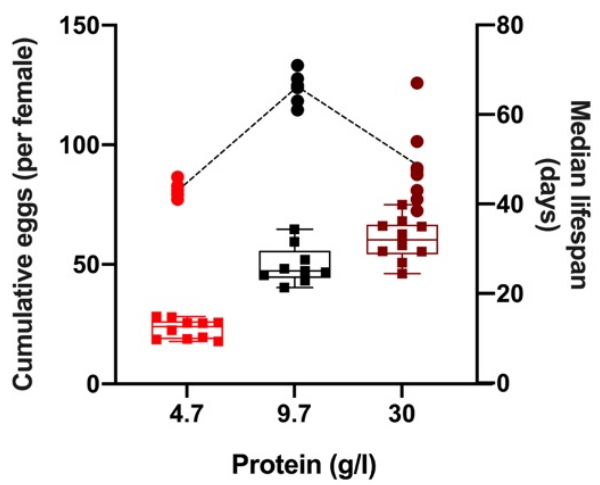

0.15

b)

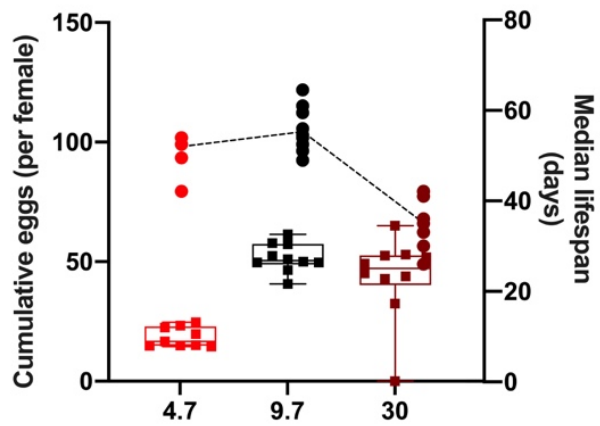

0.6

d)

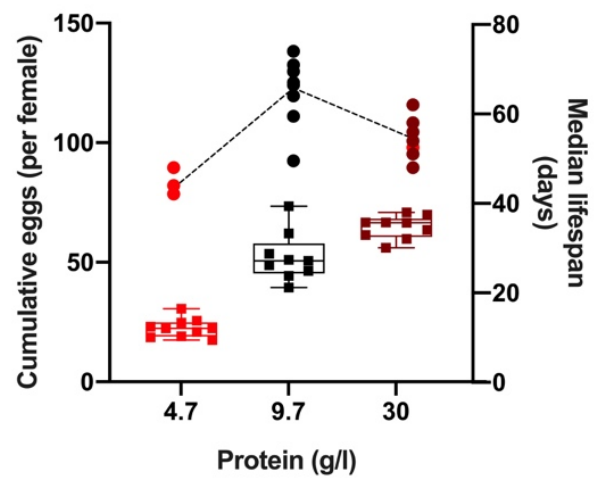

Figure 2. Dietary cholesterol content significantly modified the effect of protein content on lifespan and reproduction. Lowering cholesterol most severely compromised lifespan as protein levels increased. In general, increasing protein drove increasing levels of egg production and this was enhanced by increasing dietary cholesterol levels. Cumulative eggs laid per female are shown as box plots. Lines show the relationship between dietary protein and median survival (days) for each cholesterol level. (0g/l (a), 0.15g/l (b), 0.3g/l (c), 0.6g/l (d)). Statistical analyses reported in Supplementary Table 5 and Supplementary Table 6.

192 
195 Next, we looked to see if changing dietary cholesterol modified the responses of lifespan

196 and egg laying to variation in carbohydrate concentration (Supplementary Figure 1 c \& f;

197 Supplementary Table 5). At $0 \mathrm{~g} / \mathrm{l}$ cholesterol, lifespan was generally short (31d median) but

198 positively affected by increasing dietary carbohydrate (up to $40 \mathrm{~d}$ median) (Figure 3a). As

199 dietary cholesterol was increased to $0.15 \mathrm{~g} / \mathrm{l}$, lifespan on all diets was higher and the

200 positive effect of increasing carbohydrate was preserved (Figure 3b). However, when

201 cholesterol reached $0.3 \mathrm{~g} / \mathrm{l}$, the flies were constantly long-lived, and lifespan was unaffected

202 by dietary carbohydrate level (66d median) (Figure 3c). This pattern was not changed by

203 increasing cholesterol further to $0.6 \mathrm{~g} / \mathrm{l}$ (Figure 3d). Thus, each of our dietary carbohydrate

204 levels could support maximal fly lifespan, but the lower carbohydrate diets were more

205 susceptible to the detrimental effects of dietary cholesterol dilution.

206

207 Increasing dietary carbohydrate had a generally negative impact on egg laying and this

208 effect was modified by the benefits of increasing dietary cholesterol (Figure 3;

209 Supplementary Figure 1f; Supplementary Table 6). Without any cholesterol in the food, egg

210 laying was consistently low and was negatively affected by increasing dietary carbohydrate

211 (Figure 3a). This negative effect of carbohydrate on egg laying became stronger as

212 cholesterol was increased to $0.15 \mathrm{~g} / \mathrm{l}$ (Figure 3b) and $0.3 \mathrm{~g} / \mathrm{l}$ (Figure 3c), with no further

213 change as cholesterol increased from $0.3 \mathrm{~g} / \mathrm{l}$ to $0.6 \mathrm{~g} / \mathrm{l}$ (Figure $3 \mathrm{~d}$ ). This increasingly negative

214 relationship between carbohydrate and egg laying was caused because increasing

215 cholesterol benefited egg laying more at lower dietary carbohydrate levels - the opposite of

216 what we observed for lifespan.

218 Thus, once again fly lifespan and egg laying worsened as cholesterol was diluted, but unlike

219 its negative interaction with increasing dietary protein, the detrimental effects of lowering

220 cholesterol became stronger as carbohydrate levels decreased. This indicates that the

221 negative impact of lowering cholesterol is not a specific interaction with either high protein

222 or low carbohydrate levels in the diet. Instead lowering cholesterol produces worse

223 outcomes as the dietary protein : carbohydrate ratio increases. This is the same change in

224 macronutrient balance that promotes increasing egg laying. 
Cholesterol (g/l)

a)

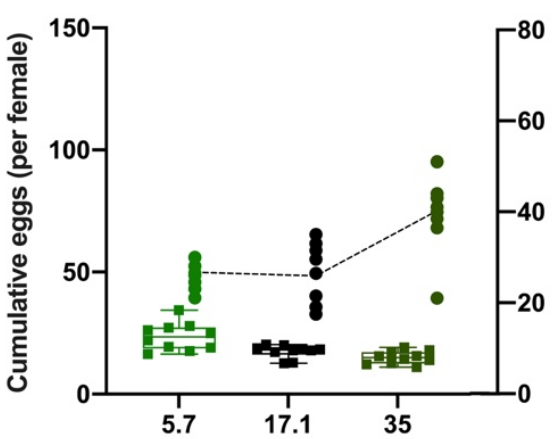

Cholesterol (g/l)

c)

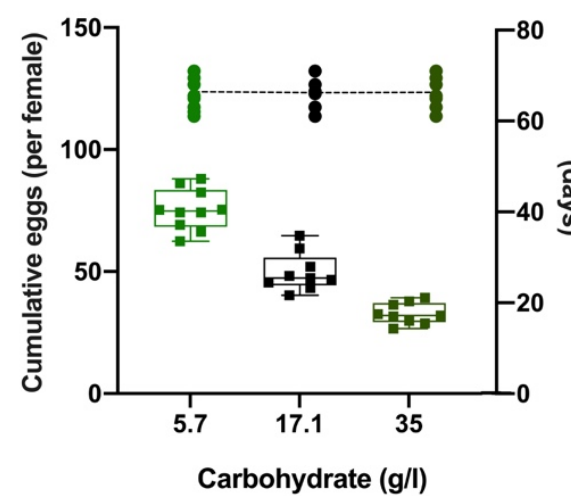

0
0.3 b)

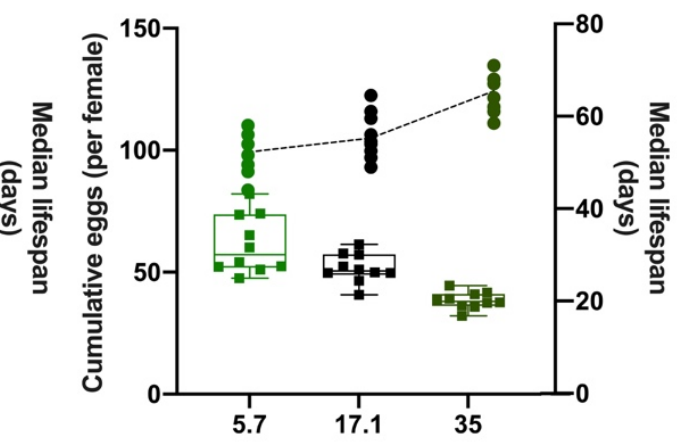

d)

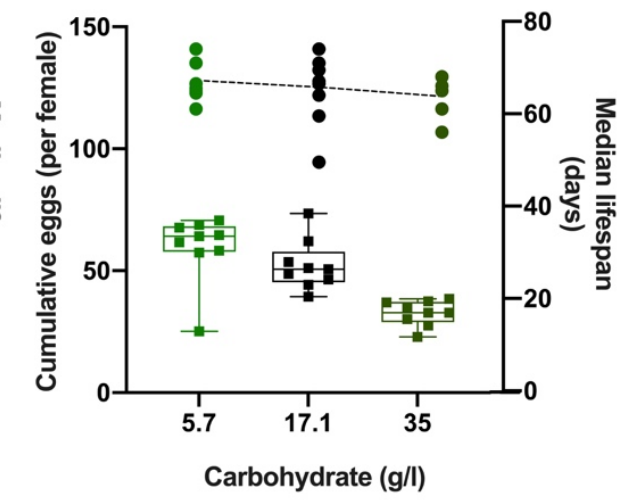

230 Figure 3. Dietary cholesterol content significantly modified the effect of carbohydrate

231 content on lifespan and on reproduction. Lowering cholesterol most severely compromised

232 lifespan as carbohydrate levels decreased - the conditions that drove increasing levels of

233 egg production. Cumulative eggs laid per female are shown as box plots. Lines show the 234 relationship between dietary carbohydrate and median survival (days) for each cholesterol 235 level. (0g/l (a), 0.15g/l (b), 0.3g/l (c), 0.6g/l (d)). Statistical analyses reported in

236 Supplementary Table 5 and Supplementary Table 6. 
Increasing the dietary protein : carbohydrate ratio drives increasing reproduction and makes fly lifespan susceptible to dietary cholesterol dilution.

244 We saw that flies produce more eggs in response to increasing dietary protein : carbohydrate ratio and that these positive effects persist even as dietary cholesterol falls to a level that cannot fully support lifespan (less than $0.3 \mathrm{~g} / \mathrm{l}$ cholesterol). Thus, the protein : carbohydrate ratio appears to take precedence over dietary sterol levels in the decision to commit to reproduction. If this is the case, we expect to see a positive relationship between the dietary protein : carbohydrate ratio and egg laying across all levels of dietary cholesterol. This is indeed what we found, although the positive relationship was modified by cholesterol level, starting with a weak positive effect on $0 \mathrm{~g} / \mathrm{l}$ cholesterol (Figure 4a) and becoming increasingly positive as cholesterol was increased to $0.15 \mathrm{~g} / \mathrm{l}$ (Figure 4b) and 0.3 $\mathrm{g} / \mathrm{l}$ (Figure 4c). Once again, increasing cholesterol from $0.3 \mathrm{~g} / \mathrm{l}$ to $0.6 \mathrm{~g} / \mathrm{l}$ promoted no further benefit (Figure 4d, Supplementary Table 7).

Reproduction can impose a cost on future survival if resources that are essential for somatic maintenance are preferentially committed to making eggs. Since increasing protein : carbohydrate levels drove increasing egg laying, even when the adults were completely deprived of sterols, it is possible that females are committing sterols to egg production at a rate faster than they can replenish it from the diet. If true, mothers on low cholesterol diets would become shorter lived as egg laying increases, but when cholesterol is sufficient, the relationship between egg production and lifespan should become less negative. To test this, we plotted egg laying against lifespan for all replicates across all diets. This showed that egg laying was a significant predictor of lifespan, and that this relationship was modified by dietary cholesterol (Supplementary Table 8). When the data are grouped by dietary cholesterol level (Figure 5), we see that when cholesterol was at 0g/l (Figure 5a), there was a negative relationship between egg laying and lifespan, but as the cholesterol level increased, the correlation flattened, such that the slope was no longer negative for each level of cholesterol supplementation (Figure 5b-d, Supplementary Table 8).

271 Thus, when dietary cholesterol was insufficient, increasing dietary protein : carbohydrate drove higher egg laying (Figure 4a) and this predicted lifespan shortening (Figure 5a) - a 
273 scenario that exemplifies the negative relationship between reproduction and lifespan in

274 response to increasing protein : carbohydrate levels that is regularly reported in the dietary

275 restriction literature (Mair et al., 2005; Lee et al., 2008; Skorupa et al., 2008; Solon-Biet et

276 al., 2014; Solon-Biet et al., 2015; Simpson et al., 2017). However, when cholesterol was

277 increased, the negative relationship was reduced such that egg laying was either completely

278 independent of lifespan (Figure $5 b$ ) or became slightly positively correlated, indicating that

279 the dietary conditions which promote egg laying are the same as those that promote longer

280 lifespan (Figure 5c-d). Thus, higher egg laying in response to increasing protein :

281 carbohydrate levels only shortens lifespan when cholesterol is insufficient to support egg

282 production.

283

284

285

286

287

288

289

290

291 


\section{Cholesterol (g/l)}

0

0.15

a)

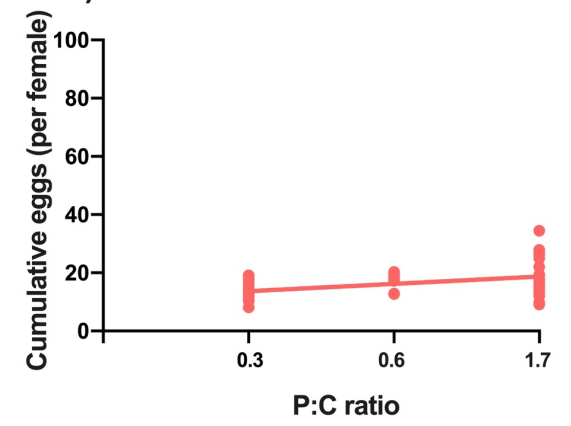

Cholesterol (g/l)
0.3

c)

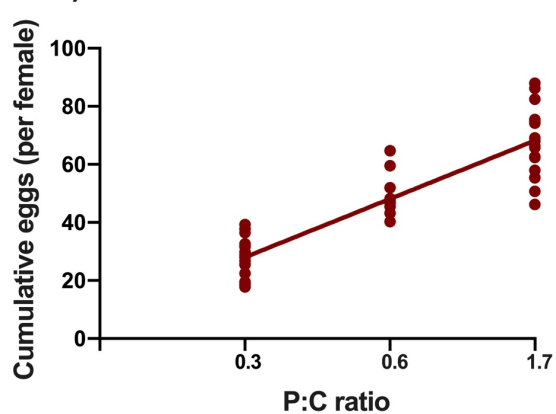

b)

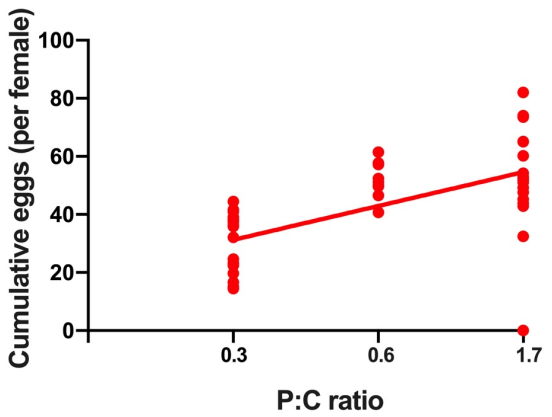

0.6 d)

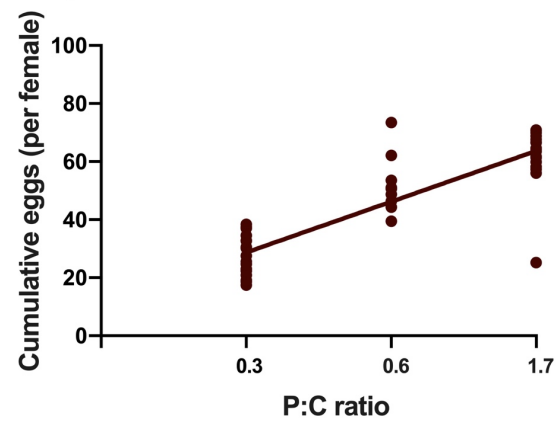

294 Figure 4. Increasing dietary protein : carbohydrate ratio resulted in increased egg production at every level of cholesterol. This positive effect was stronger from $0 \mathrm{~g} / \mathrm{l}$ cholesterol (a) to $0.15 \mathrm{~g} / \mathrm{l}(\mathrm{b})$ and $0.3 \mathrm{~g} / \mathrm{l}$ (c). There was no additional benefit of further increasing cholesterol to $0.6 \mathrm{~g} / \mathrm{l}$ (d). Regression lines show the relationship between cumulative eggs laid per female and protein : carbohydrate ratio. Statistical analysis reported in Supplementary Table 7. 


\section{Cholesterol (g/l)}

a)

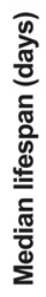

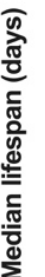

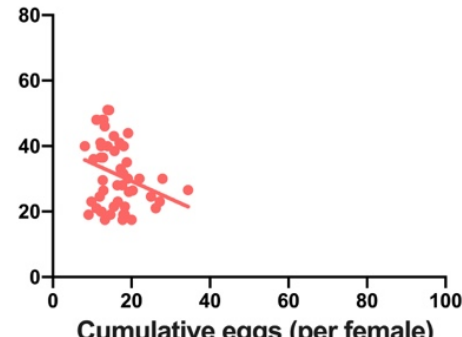

Cholesterol (g/l)

c)

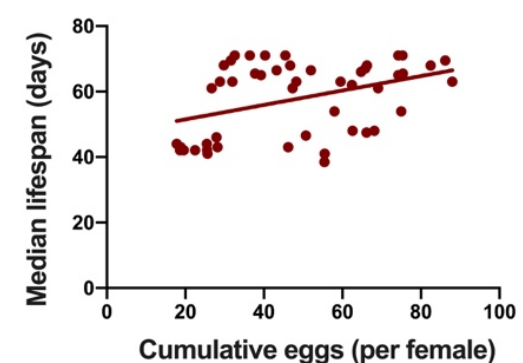

0.15

b)
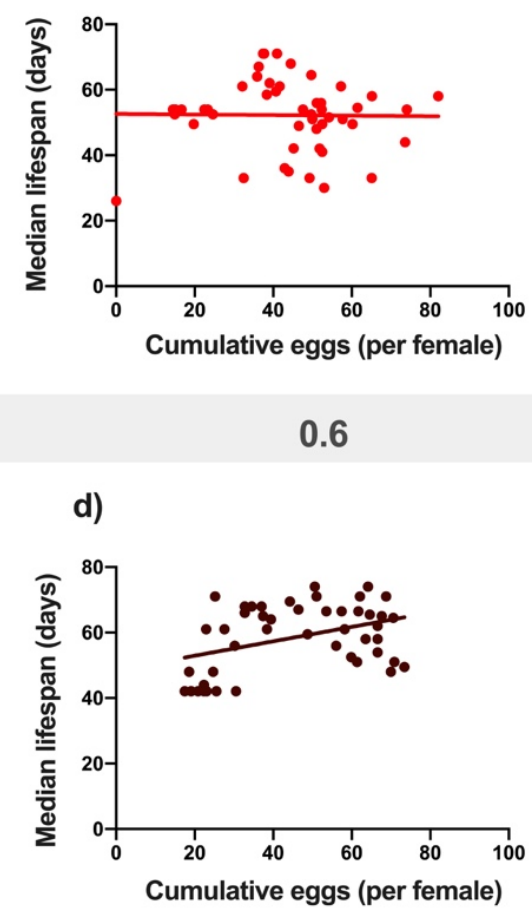

0.6

d)

0.3

umulative eggs (per female)

Figure 5. Providing adequate cholesterol transforms the relationship between egg production and lifespan from negative to positive. When cholesterol was not available $(0 \mathrm{~g} / \mathrm{l})$ (a), there was a negative relationship between egg laying and lifespan as dietary protein and carbohydrate levels were varied. When cholesterol was provided at $(0.15 \mathrm{~g} / \mathrm{l})(\mathrm{b})$ or above $(\mathrm{c}$, d), this negative relationship was eliminated and egg production varied independently of

309 lifespan. Regression lines show the relationship between cumulative eggs laid per female and median survival (days) in response to varying levels of cholesterol availability. Statistical analysis reported in Supplementary Table 8.

\section{Lifespan extension by rapamycin depends on dietary cholesterol level}

316 TOR signalling is a key amino acid signalling pathway that is critical for growth, reproduction

317 and lifespan. Because TOR activity increases with dietary protein levels, it has been

318 implicated as mediating the detrimental effects on lifespan of high protein diets (Liu \&

319 Sabatini, 2020). This is supported by the fact that rapamycin, a pharmacological suppressor

320 of TOR, has been shown to extend lifespan across numerous species, including Drosophila

321 where it also suppresses egg production (Bjedov et al., 2010; Schinaman, Rana, Ja, Clark, \& 
322 Walker, 2019; Scialò et al., 2015). If cholesterol limitation is the reason why high egg

323 production on high protein : carbohydrate diets causes reduced lifespan, rapamycin might

324 extend lifespan because it reduces egg production and therefore rescues females from

325 cholesterol depletion. If true, rapamycin should extend life only when the flies on high

326 protein : carbohydrate diets are cholesterol limited.

327

328 As before, when we maintained flies on a high protein : carbohydrate diet, increasing

329 dietary cholesterol from $0.1 \mathrm{~g} / \mathrm{l}$ to $0.3 \mathrm{~g} / \mathrm{l}$ increased lifespan $(62 \mathrm{~d}$ median $\vee 69 \mathrm{~d}$

330 median)(Figure 6a). Egg laying was also slightly (34\%), but significantly, elevated by

331 cholesterol supplementation (Figure $6 \mathrm{~b}$ ) indicating that $0.1 \mathrm{~g} / \mathrm{l}$ cholesterol was limiting for

332 both lifespan and reproduction. When rapamycin was added to both foods, egg laying was

333 almost completely suppressed (Figure 6b). Rapamycin also extended fly lifespan, but only

334 for flies on low dietary cholesterol $(0.1 \mathrm{~g} / \mathrm{l})$ (Figure 6a), bringing their lifespan up to the same

335 level as flies on higher cholesterol food ( $0.3 \mathrm{~g} / \mathrm{l} ; 69 \mathrm{~d}$ median). Adding rapamycin to the food

336 with higher cholesterol did not result in any additional lifespan improvement over what was

337 already achieved by increasing cholesterol alone (69 d median; Figure 6a).

339 These data show that lifespan extension by rapamycin administration is conditional on the

340 flies being on a low cholesterol diet. Together, our data are consistent with the fly's lifespan

341 being determined by having access to sufficiently high levels of dietary sterols that they

342 have enough left over after reproduction to meet their needs for somatic maintenance. This

343 can be achieved either by enriching the amount of cholesterol in the diet, or by reducing the

344 flies' expenditure on egg production, which can be achieved by reducing the dietary protein

345 : carbohydrate ratio or by suppressing egg production pharmacologically. 
a)

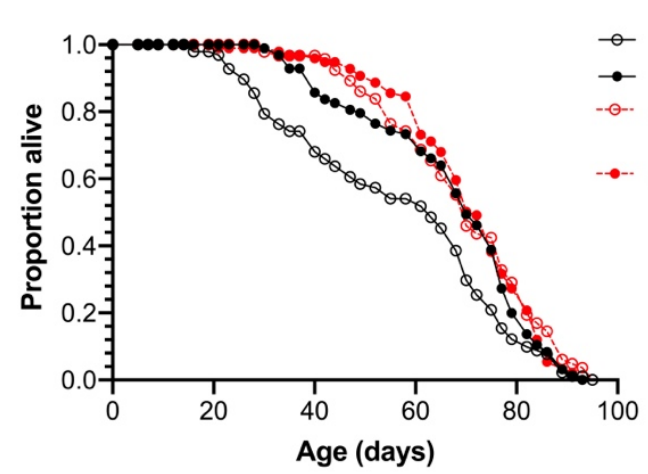

b)

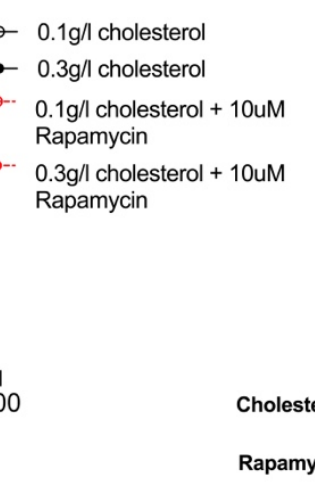

$0.1 \mathrm{~g} / \mathrm{l}$ cholesterol

$0.3 \mathrm{~g} / \mathrm{l}$ cholesterol

$0.1 \mathrm{~g} / \mathrm{l}$ cholesterol $+10 \mathrm{uM}$ Rapamycin

$3 \mathrm{~g} / \mathrm{l}$ cholesterol + 10uM apamycin

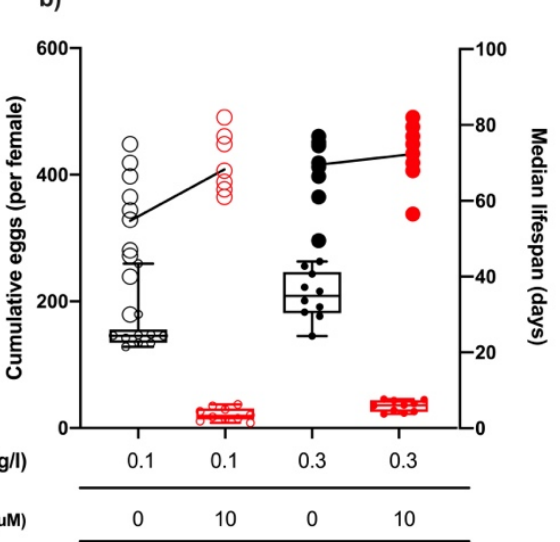

350

351

352

353

354

355

356

357

358

359

360

361

362

363

364 The experiments above were all performed using synthetic diets in which our ability to vary

Figure 6. Rapamycin extends lifespan in flies consuming a low cholesterol diet $(0.1 \mathrm{~g} / \mathrm{l})$ but had no effect when cholesterol level was increased to $0.3 \mathrm{~g} / \mathrm{l}$. (a) There was no significant difference in lifespan among flies fed $0.3 \mathrm{~g} / \mathrm{I}$ cholesterol, $0.3 \mathrm{~g} / \mathrm{I}$ cholesterol + rapamycin or $0.1 \mathrm{mg} / \mathrm{I}$ cholesterol + rapamycin, all of which were significantly longer lived than flies fed $0.1 \mathrm{~g} / \mathrm{l}$ cholesterol $(0.1 \mathrm{~g} / \mathrm{v} 0.3 \mathrm{~g} / \mathrm{l}, P=0.014 ; 0.1 \mathrm{~g} / \mathrm{l}$ v $0.1 \mathrm{~g} / \mathrm{l}+$ rapamycin, $P<0.001 ; 0.1 \mathrm{~g} / \mathrm{l}$ v $0.3 \mathrm{~g} / \mathrm{l}+$ rapamycin, $P=0.002$, log rank test). (b) Cumulative eggs laid were significantly reduced in flies treated with rapamycin $(P<0.001$, ANOVA), and also significantly reduced when cholesterol was limited ( $p<0.001$, ANOVA).

\section{Standard yeast-based media used in the laboratory contains lifespan limiting levels of} sterols the absolute and relative concentrations of protein, carbohydrate, and sterol are limited only by solubility. However, most laboratories maintain fly populations on a diet that consists of yeast and sugar as well as variable numbers of other ingredients (Piper, 2017). Although the relative concentration of each nutrient in yeast is more constrained than on our synthetic diet, systematic studies have shown that the type and commercial source of yeast can have significant effects on overall dietary composition (Lesperance \& Broderick, 2020) and the relationship between lifespan and egg laying (Bass et al, 2007). In Bass et al. (2007), the most dramatic lifespan reduction for increasing yeast was found when the fly food was made with a water-soluble extract of yeast that would contain very little, if any, sterols. Thus, similar to what we demonstrated on the synthetic diet, the shortening of fly 
375 lifespan when increasing the yeast content (protein : carbohydrate ratio) in lab foods may

376 be caused by an insufficiency of dietary sterols.

377

378 We tested the effects of supplementing cholesterol into two sugar / yeast recipes that have

379 been commonly used to study the effects of dietary restriction on lifespan (Mair et al., 2005;

380 Bass et al., 2007; Katewa et al., 2016). These diets differ in both the number of ingredients

381 used and the type of yeast; while both are Saccharomyces cerevisiae, one is a whole cell

382 autolysate, while the other is a water-soluble extract. Adding $0.3 \mathrm{~g} / \mathrm{l}$ cholesterol to both the

383 low yeast (dietary restriction) and high yeast foods of both yeast types had a significant

384 positive effect on lifespan (Figure 7a, c) and egg laying (Figure 7b, d) when compared to

385 diets without cholesterol supplementation. The magnitude of this benefit to lifespan was

386 greater for flies on the high yeast foods than on the low yeast foods, meaning that

387 cholesterol supplementation narrowed the difference between the dietary restriction vs

388 high yeast diet from $9 \%$ to $4 \%$ for flies on the autolysed yeast diets (Figure $7 a$ ) and from $81 \%$

389 to $25 \%$ lifespan extension for flies on the yeast extract diets (Figure 7c). We note that even

390 with cholesterol supplementation, the flies on the high yeast diet were still significantly

391 shorter lived than those on the cholesterol supplemented low yeast food. This small

392 additional cost of the high yeast food could reflect a detrimental (toxic) effect on lifespan of

393 very high dietary protein, similar to what we observed in our highest protein diets on the

394 synthetic foods (Figure 2 c, d). This is not rescuable by cholesterol supplementation and is

395 not related to the number of eggs that females produce. 
a)

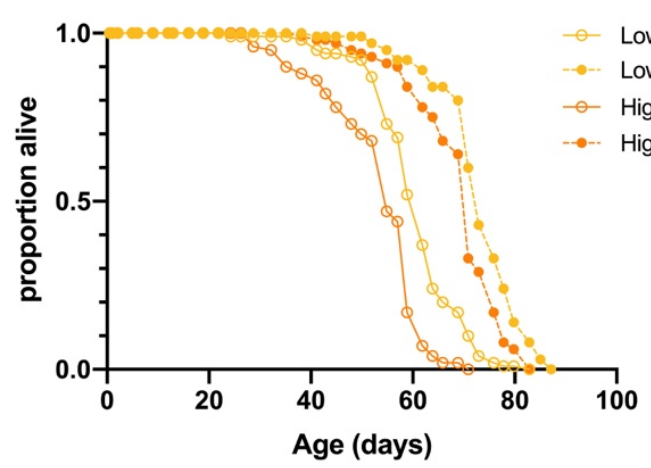

b)

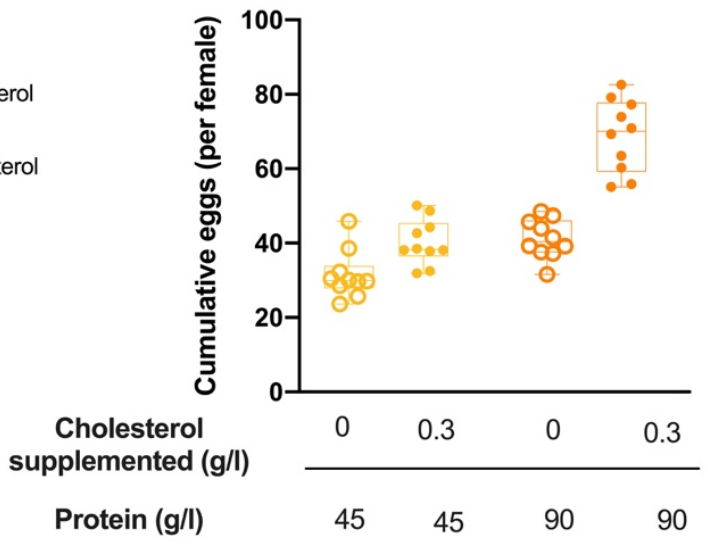

c)

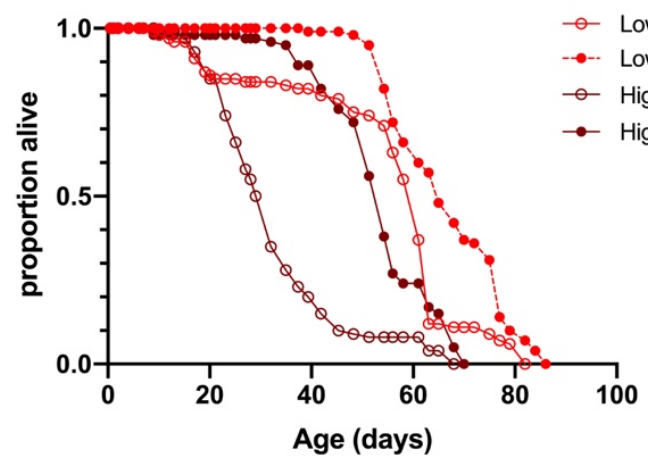

Yeast extract

High yeast

High yeast + choelsterol d)

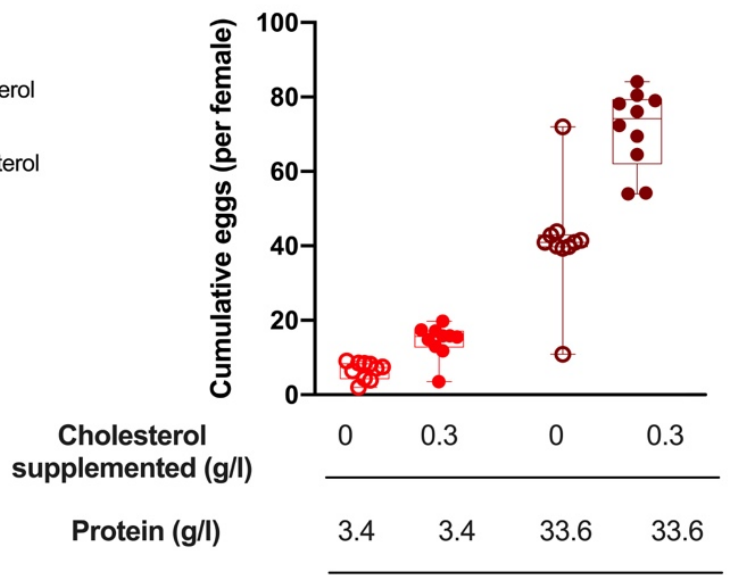

Figure 7. Cholesterol supplementation significantly extended lifespan and promoted egg laying of flies fed yeast-based diets. (a) Adding dietary cholesterol significantly increased the

410 lifespan of flies on both high and low concentrations of diets made with autolysed yeast

411 (low yeast $v$ low yeast+cholesterol and high yeast $v$ high yeast + cholesterol; $P<0.001, \log$

412 rank test). (b) Yeast and cholesterol addition to these two foods both positively affected egg 413 production $(P<0.001$, two-way ANOVA). (c) Cholesterol addition significantly extended the 414 lifespan of flies on diets made with yeast extract (low YE v low YE+cholesterol and high YE v 415 high YE + cholesterol; $P<0.001$, log rank test). (d) Cumulative egg laying was also positively 416 affected by yeast addition and cholesterol addition to each yeast level $(P<0.001$, two-way 417 ANOVA). 


\section{Discussion}

424 The reason that higher protein : carbohydrate diets shorten lifespan in DR studies is routinely attributed to their direct effects on nutrient signalling pathways and physiology.

426 However our data implicate a fundamentally different mechanism, in which the macronutrients act indirectly, by manipulating sterol availability, which then modifies lifespan. Specifically, diets with high protein : carbohydrate ratios decrease lifespan by causing mothers to overinvest limiting sterols into egg production. Thus, although the macronutrients set egg laying rates, it is actually the sterols that determine lifespan due to a trade-off with reproduction. The corollary of this finding is that the lifespan of flies on high protein : carbohydrate diets can be extended by increasing the supply of cholesterol. This approach is the opposite of, but complementary to, the already recognised strategies to extend lifespan by DR, which reduce maternal investment into reproduction by decreasing the dietary protein : carbohydrate ratio (Mair et al., 2005; Lee et al., 2008; Skorupa et al., 2008) or by treating the animals with rapamycin that suppresses TOR and reduces reproduction (Bjedov et al., 2010; Harrison et al., 2009; Liu \& Sabatini, 2020). It is also consistent with our recent work that showed non-reproducing adult males and genetically sterile females suffer little to no lifespan cost when sterol deprived, which is presumably because they conserve sterols which would otherwise be depleted by reproduction (Wu et al, 2020).

High protein diets promote egg production, driving a lethal micronutrient deficiency

In the lab, flies can be successfully reared and maintained on a mixture of just sugar and yeast (Pearl \& Parker, 1921). This diet is thought to reflect their natural diet of rotting fruit and the microbial community - principally the yeasts - that cause the fruit to decay (Markow et al., 2015; Piper, 2017). Yeast contains all of the nutrients that flies require, 449 including protein ( $\sim 5 \%)$, carbohydrate ( $\sim 40 \%)$, a small amount of fat ( $7 \%)$, nucleic acids

450 ( 7\%), and micronutrients, such as sterols, metal ions and vitamins, which are essential for 451 flies. Drosophila rely heavily on protein from yeast, as well as carbohydrate from both yeast and plant sources, to guide their feeding behaviour. They select amongst foods containing the appropriate protein and carbohydrate concentrations to enhance their fitness (Ribeiro \& 
454 Dickson, 2010; Vargas et al., 2010; Walker et al., 2017). Many of the other nutrients from

455 their diet, including sterols, do not affect feeding behaviour, presumably because they are normally acquired in adequate quantities as part of a diet that is sufficient in macronutrients (Walker, et al. , 2015; Leitão-Gonçalves et al., 2017; Münch et al., 2020).

While the relative proportion of protein and carbohydrate in yeast remains relatively constant across growth conditions, the abundance of sterols can vary over a 10 -fold range in response to changes in oxygen availability, which is essential for sterol biosynthesis (Starr \& Parks, 1962; Wilson \& McLeod, 1976). Thus, because fly feeding behaviour and egg production are almost entirely shaped by the macronutrients, fly lifespan is susceptible to reductions in the sterol : protein content of dietary yeast. Our data indicate that this is because protein drives sterols to be preferentially partitioned towards reproduction at the expense of maintaining the adult soma. While we have found this to be the case for flies feeding on lab based foods, it is also reasonable to expect it for flies feeding on rotting fruit, where microbial growth is largely fermentative (driven by high sugar levels and limiting oxygen), producing ethanol and short chain acids to which Drosophila has evolved a healthy tolerance (Geer et al., 1993).

\section{Extending fly lifespan by DR involves an indirect trade-off}

There have been several theoretical attempts to describe the mechanistic basis for the lifespan benefits of dietary restriction (Blagosklonny, 2006, 2010; Kirkwood \& Rose, 1991; Moatt et al., 2020; Regan et al., 2020; Speakman, 2020). In particular, the disposable soma theory proposes that organisms will strategically reallocate nutrients towards somatic maintenance at the cost of reproduction when nutrients are scarce and that this enhances lifespan (Kirkwood \& Rose, 1991). Our data indicate that this trade-off can exist for flies

480 feeding on yeast, but only when dietary sterols are limiting. However, when dietary sterols 481 are not limiting, this trade-off does not need to exist and a single nutritional optimum for 482 both lifespan and reproduction can be found. Thus, the macronutrient balance that drives 483 higher egg laying does not necessarily inflict a direct cost on lifespan. 
In mechanistic work, the increased lifespan under dietary restriction has been attributed to the benefits of reduced dietary protein, which enhances proteome maintenance via reduced TOR signalling (Harrison et al., 2009; Partridge et al., 2011; Kapahi et al., 2017; Piper et al., 2017; Sabatini, 2017; Dobson et al., 2018; Liu \& Sabatini, 2020). However, we have shown that flies on a high protein : carbohydrate diet, in which TOR signalling would be expected to remain high, can still sustain a long lifespan if supplemented with cholesterol, or alternatively, if the cost of reproduction on sterol stores is removed by making flies infertile (Wu et al, 2020). This demonstrates that the major improvement to lifespan observed on low protein diets is not the result of enhanced proteostasis, but is instead, a side effect of avoiding sterol depletion caused by egg production. It is likely that a deficiency of this essential micronutrient could compromise the integrity of critical tissues, such as the gut, whose quality is strongly associated with lifespan changes under dietary restriction (Rera et al., 2013; Regan et al., 2016).

We note that while dietary sterols can account for the dietary restriction effect seen for flies feeding on yeast, other limiting micronutrients could be key for explaining the lifespan benefits of dietary restriction in other organisms. If true, supplementing their high food diets with limiting micronutrient(s) should mimic the benefits of dietary macronutrient remodelling as sterol supplementation did for flies in our experiments.

\section{Conclusion}

507 Our data show that the detrimental effects of a high protein : carbohydrate diet on lifespan

508 in female Drosophila melanogaster are, to a significant extent, driven by an indirect nutrient 509 trade-off, in which the macronutrients drive maternal sterol depletion by enhancing egg

510 laying. This is a fundamentally different mechanism from the predominant view

511 that reducing protein : carbohydrate balance in diets improves lifespan by a direct action to 512 reduce TOR signalling and enhance proteostasis. Because of our discovery, we show that the 513 shortened lifespan of flies on a high protein : carbohydrate diet can be improved by

514 supplementing their diet with cholesterol, as well as by reducing egg production by lowering 515 the dietary protein : carbohydrate ratio or by administering rapamycin. Further work is now 516 needed to discover the mechanisms through which cholesterol works to modify lifespan in 
bioRxiv preprint doi: https://doi.org/10.1101/2020.08.21.260489; this version posted August 21,2020 . The copyright holder for this preprint

(which was not certified by peer review) is the author/funder, who has granted bioRxiv a license to display the preprint in perpetuity. It is made available under aCC-BY-NC-ND 4.0 International license.

517 Drosophila melanogaster, and the role of other important micronutrients in healthy ageing

518 across taxa. 
Methodology

Fly husbandry:

523 All experiments were conducted using a wild type Drosophila melanogaster strain called

524 Dahomey (Mair et al., 2005). These flies have been maintained in large numbers with overlapping generations to maintain genetic diversity. Upon removal from their population cages, flies were reared for two generations at a controlled density before use in experiments, to control for possible parental effects. Eggs for age-synchronised flies were collected over 18 hours, and the resulting adult flies emerged during a 12-hr window. They were then allowed to mate for $48 \mathrm{hr}$ before being anaesthetised with $\mathrm{CO} 2$, at which point females were separated and allocated into experimental vials. Stocks were maintained and experiments were conducted at $25^{\circ} \mathrm{C}$ on a $12 \mathrm{hr}: 12 \mathrm{hr}$ light:dark cycle at $65 \%$ humidity (Bass et al., 2007).

Lifespan assays:

For all lifespan assays, flies were placed into vials (FS32, Pathtech) containing $3 \mathrm{ml}$ of treatment food at a density of ten flies per vial, with ten replicate vials per treatment. Flies were transferred to fresh vials every two to three days at which point deaths and censors were recorded and saved using the software package Dlife (Linford et al., 2013; Piper \& Partridge, 2016).

Fecundity assays:

544 Fecundity was measured as the sum of the mean number of eggs laid per female once per

545 week over four weeks (commencing on day 8 of the experiment), except for the sugar yeast

546 (SY) medium experiment, for which egg counts were recorded in weeks one, two and

547 three. These timepoints were selected because measuring reproductive output during the

548 first weeks of egg laying has shown to be representative of life-long fecundity in flies

549 (Chapman \& Partridge, 1996). The eggs laid on the food surfaces of all vials were

550 imaged using a web camera mounted on a Zeiss dissecting microscope and eggs were 
counted both manually and using Quantifly (Waithe et al., 2015). Quantifly was trained using five images for each cholesterol concentration due to variance in food opacity.

Experimental Diets:

Holidic medium experiments

To examine the effects of protein: carbohydrate ratio on lifespan and fecundity we chose five experimental diets that consisted of three different protein (amino acid): carbohydrate (sucrose) ratios at three levels of similar caloric densities (Figure 1a, Table 1). These diets also made up a three-diet series of protein only dilution, and a three-diet series of carbohydrate only dilution (Figure 1a). The two diet series had one diet in common, which was our most commonly used, "standard" lab diet (Piper et al, 2014). These diets incorporate those known to maximise either lifespan, reproduction or both (Ma et al., 2020; Piper et al., 2017). To examine the effects of cholesterol on these traits, we selected four cholesterol concentrations for each of these five diets, making a total of 20 diets (Figure $1 \mathrm{~b}$, Table 1). All diets were made using the holidic medium described in Piper et al. (2014), in which free amino acids are used to make up protein equivalents. To convert amino acids to protein equivalents, we used the molar quantities of nitrogen and the assumption that $\mathrm{N}$ makes up $16 \%$ of whole proteins (Sosulski and Imafidon, 1990). In this case, an amino acid ratio matched to the exome of adult flies (Flyaa) was utilised, (Ma et al., 2020; Piper et al., 2017). Finally, for practical reasons we used cholesterol in the diet as opposed to ergosterol, because it is easily accessible, and where studied, has been shown to be adequate to support drosophila adult nutrition to the same extend as a yeast-based diet (Piper et al., 2014). 
a)

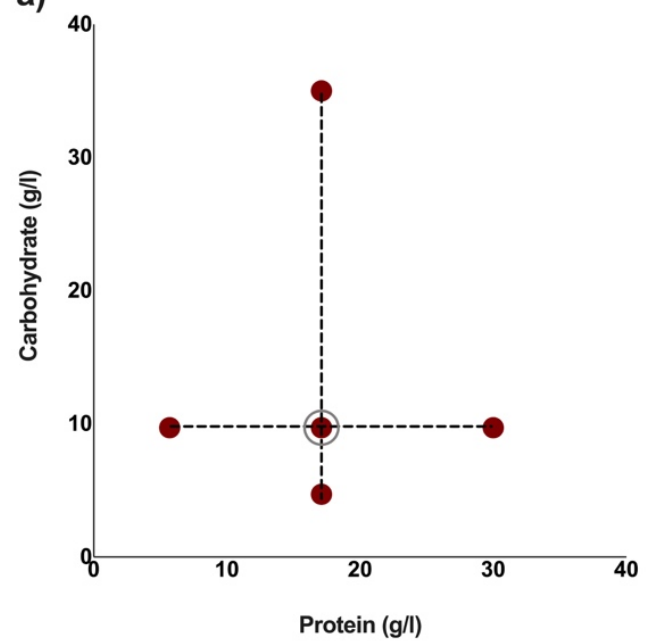

b)

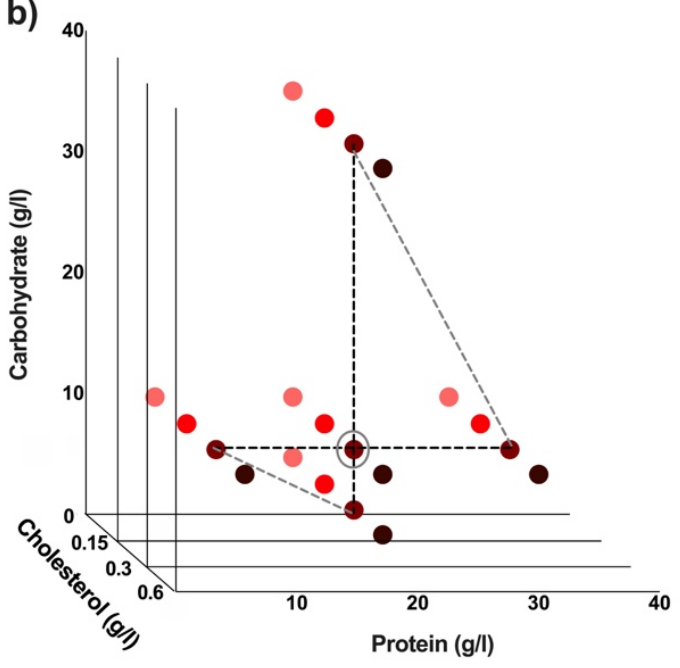

582

583

584

585

586

587

588

589

590

591

592

593

594

595

596

597

598

599

600

601

602

603

604

605

Figure 1. Experimental diets used are indicated by coloured dots. These diets have varying protein : carbohydrate ratios. This makes a total of five different experimental diets (a). The standard cholesterol concentration is $0.3 \mathrm{~g} / \mathrm{l}$. Three additional cholesterol concentrations were used for each of the five protein : carbohydrate ratios to make a total of 20 different experimental diets (b). Diets which are either protein constant or carbohydrate constant are connected by black dotted lines, and diets with comparable caloric concentrations are connected by grey dotted lines $(a, b)$. The standard diet used in our laboratory is circled in grey $(a, b)$. 
606 Table 1. Protein: carbohydrate ratio, along with the nutrient densities, cholesterol

607 concentration and caloric content, for all synthetic experimental diets used. In the holidic

608 media, amino acids are used to make up protein equivalents. To convert amino acids to

609 protein equivalents, we used the molar quantities of nitrogen and the assumption that $\mathrm{N}$

610 makes up $16 \%$ of whole proteins (Imafidon \& Sosulski, 1990). Calories were calculated using

611 the method described in Southgate and Durnin (1970).

612

\begin{tabular}{|c|c|c|c|c|c|c|}
\hline Diet & $\begin{array}{l}\text { Protein: } \\
\text { carbohydrate } \\
\text { equivalent }\end{array}$ & $\begin{array}{l}\text { Sum } \\
\text { mass of } \\
\text { amino } \\
\text { acids (g/ } \\
\text { L) }\end{array}$ & $\begin{array}{l}\text { Equivalent } \\
\text { protein (g/L) }\end{array}$ & $\begin{array}{l}\text { Carbohydrate (g/ } \\
\mathrm{L})^{2}\end{array}$ & $\begin{array}{l}\text { Cholesterol } \\
(\mathrm{g} / \mathrm{l})\end{array}$ & $\begin{array}{l}\text { Estimated } \\
\text { caloric } \\
\text { content } \\
\text { (kcal/L) }\end{array}$ \\
\hline 1 & $1: 0.6$ & 5.25 & 4.7 & 17.1 & 0 & 90.68 \\
\hline 2 & 1:0.6 & 5.25 & 4.7 & 17.1 & 0.15 & 90.68 \\
\hline 3 & 1:0.6 & 5.25 & 4.7 & 17.1 & 0.3 & 90.68 \\
\hline 4 & 1:0.6 & 5.25 & 4.7 & 17.1 & 0.6 & 90.68 \\
\hline 5 & 1:0.6 & 10.74 & 9.7 & 35 & 0 & 186.05 \\
\hline 6 & 1:0.6 & 10.74 & 9.7 & 35 & 0.15 & 186.05 \\
\hline 7 & 1:0.6 & 10.74 & 9.7 & 35 & 0.3 & 186.05 \\
\hline 8 & 1:0.6 & 10.74 & 9.7 & 35 & 0.6 & 186.05 \\
\hline 9 & 1:1.8 & 10.74 & 9.7 & 17.1 & 0 & 118.93 \\
\hline 10 & $1: 1.8$ & 10.74 & 9.7 & 17.1 & 0.15 & 118.93 \\
\hline $11^{1}$ & 1:1.8 & 10.74 & 9.7 & 17.1 & 0.3 & 118.93 \\
\hline 12 & 1:1.8 & 10.74 & 9.7 & 17.1 & 0.6 & 118.93 \\
\hline 13 & $1: 3.6$ & 33.1 & 30 & 17.1 & 0 & 233.63 \\
\hline 14 & 1:3.6 & 33.1 & 30 & 17.1 & 0.15 & 233.63 \\
\hline 15 & $1: 3.6$ & 33.1 & 30 & 17.1 & 0.3 & 233.63 \\
\hline 16 & 1:3.6 & 33.1 & 30 & 17.1 & 0.6 & 233.63 \\
\hline 17 & 1:3.6 & 10.74 & 9.7 & 5.7 & 0 & 76.18 \\
\hline 18 & 1:3.6 & 10.74 & 9.7 & 5.7 & 0.15 & 76.18 \\
\hline 19 & 1:3.6 & 10.74 & 9.7 & 5.7 & 0.3 & 76.18 \\
\hline 20 & $1: 3.6$ & 10.74 & 9.7 & 5.7 & 0.6 & 76.18 \\
\hline
\end{tabular}

$613{ }^{1}$ Standard diet.

$614{ }^{2}$ Carbohydrate is added to the diet as sucrose

615 Rapamycin experiment 
616 The same methods for making the holidic medium described above were used to make all

617 diets used in the rapamycin experiment. In this case however $18.9 \mathrm{~g} / \mathrm{l}$ protein: $17.1 \mathrm{~g} / \mathrm{l}$

618 carbohydrate were used. Cholesterol was supplemented so that its final concentration in

619 food was $0.1 \mathrm{~g} / \mathrm{l}$ and rapamycin was added to a final concentration in the diet of $10 \mathrm{uM}$. Diets

620 were either un-supplemented, supplemented with cholesterol, rapamycin, or both.

Yeast based experiments

624 Four sugar/yeast (SY) diets were created using sucrose (Bundaberg Sugar, Melbourne 625 Distuributors) and either whole yeast autolysate (MP Biomedicals, LLC, \#903312) or yeast 626 extract (Bacto Yeast Extract, \#212750). These diets correspond to previously published 627 conditions for fully fed and dietary restriction (dietary restriction) conditions (Bass et al., 628 2007; Katewa et al., 2016; Mair et al., 2005). The fully fed diets contained, per litre, 50g 629 sucrose and $100 \mathrm{~g}$ autolysed yeast or $50 \mathrm{~g}$ sucrose, $50 \mathrm{~g}$ yeast extract plus $86 \mathrm{~g}$ of cornmeal 630 (The Full Pantry, Victoria, Australia). The dietary restriction diets contained, per litre 50g 631 sucrose and $200 \mathrm{~g}$ autolysed yeast or $50 \mathrm{~g}$ sucrose, $5 \mathrm{~g}$ yeast extract plus $86 \mathrm{~g}$ cornmeal. To 632 each of these diets, we added cholesterol (Glentham Life Sciences, GEO100, \#100IEZ) at a 633 concentration of either 0 or $0.3 \mathrm{~g} / \mathrm{l}$ (Figure 2, Table 3). Cholesterol was added to all diets as a 634 powder which was mixed in with all other dry ingredients prior to cooking. This gave us a 635 total of four experimental diets per yeast.

636

\section{Statistical analyses}

639 All statistical analyses were performed using R (version 3.3.0, available from http://www.R-

640 project.org/). Linear mixed effect models were used to analyse all data obtained using the 641 holidic media, along with egg data for yeast based diets. For the analysis of data obtained 642 using the holidic media, a model reduction was performed by stepwise removal of the most 643 complex non-significant term until any further removal significantly reduced the model fit. 644 Log rank tests were used to compare the survival curves in the rapamycin experiment and 645 yeast based dietary experiments. Finally, an ANOVA was used to analyse egg laying results 646 for the rapamycin experiment. Plots were made in Graphpad Prism (version 8.4.2) 


\section{Acknowledgements}

649

650 We would like to thank Amy Dedman from Monash University for technical assistance, Xiaoli

651 He and Dr. Mingyao Yang (University College London at the time) for contributions to the

652 early phase of these experiments, as well as Lisa Rapley (Monash University) for help with

653 eggs counts.

654

655

656

657

658

659

660

661

662

663

664

665

666

667

668

669

670

671

672

673

674

675

676

677

678 
679

680

681

682

683

684

685

686

687

688

689

690

691

692

693

694

695

696

697

698

699

700

701

702

703

704

705

706

707

\section{References}

Ayala, V., Naudı, A., Sanz, A., Caro, P., Portero-otin, M., Barja, G., \& Pamplona, R. (2007). Dietary Protein Restriction Decreases Oxidative Protein Damage, Peroxidizability Index, and Mitochondrial Complex I Content in Rat Liver. Journal of Gerontology: Biological Sciences, 62(4), 352-360. https://doi.org/10.1093/gerona/62.4.352

Bass, T. M., Grandison, R. C., Wong, R., Martinez, P., Partridge, L., \& Piper, M. D. W. (2007). Optimization of Dietary Restriction Protocols in Drosophila. J Gerontol A Biol Sci Med Sci, 62(10), 1071-1081. https://doi.org/10.1093/gerona/62.10.1071

Bjedov, I., Toivonen, J. M., Kerr, F., Slack, C., Jacobson, J., Foley, A., \& Partridge, L. (2010). Mechanisms of Life Span Extension by Rapamycin in the Fruit Fly Drosophila melanogaster. Cell Metabolism, 11(1), 35-46. https://doi.org/10.1016/j.cmet.2009.11.010

Blagosklonny, M. V. (2006). Aging and immortality: Quasi-programmed senescence and its pharmacologic inhibition. Cell Cycle, 5(18), 2087-2102. https://doi.org/10.4161/cc.5.18.3288

Blagosklonny, M. V. (2010). Revisiting the antagonistic pleiotropy theory of aging: TORdriven program and quasi-program. Cell Cycle, 9(16), 3171-3176.

$$
\text { https://doi.org/10.4161/cc.9.16.13120 }
$$

Campisi, J., Kapahi, P., Lithgow, G. J., Melov, S., Newman, J. C., \& Verdin, E. (2019). From discoveries in ageing research to therapeutics for healthy ageing. Nature, 571(7764), 183-192. https://doi.org/10.1038/s41586-019-1365-2

Carvalho, M., Schwudke, D., Sampaio, J. L., Palm, W., Riezman, I., Dey, G., ... Eaton, S. (2010). Survival strategies of a sterol auxotroph. Development, 137(21), 3675-3685. https://doi.org/10.1242/dev.044560

Chapman, T., \& Partridge, L. (1996). Female fitness in Drosophila melanogaster: An interaction between the effect of nutrition and of encounter rate with males. Proceedings of the Royal Society B: Biological Sciences, 263(1371), 755-759. https://doi.org/10.1098/rspb.1996.0113 
708

709

710

711

712

713

714

715

716

717

718

719

720

721

722

723

724

725

726

727

728

729

730

731

732

733

734

735

736

Chong, A. S. C., Ishak, S. D., Osman, Z., \& Hashim, R. (2004). Effect of dietary protein level on the reproductive performance of female swordtails Xiphophorus helleri (Poeciliidae). Aquaculture, 234(1-4), 381-392. https://doi.org/10.1016/j.aquaculture.2003.12.003

Colman, R. J., Anderson, R. M., Johnson, S. C., Kastman, E. K., Kosmatka, K. J., Beasley, T. M., ... Weindruch, R. (2009). Dietary restriction delays disease onset and mortality in rhesus monkeys. Science 325, 201-204 (2009). Science (New York, N.Y.), 325(5937), 201-204. https://doi.org/10.1126/science.1173635.Caloric

Dobson, A. J., He, X., Blanc, E., Bolukbasi, E., Feseha, Y., Yang, M., \& Piper, M. D. W. (2018). Tissue-specific transcriptome profiling of Drosophila reveals roles for GATA transcription factors in longevity by dietary restriction. Npj Aging and Mechanisms of Disease, 4(1). https://doi.org/10.1038/s41514-018-0024-4

Fanson, B. G., Fanson, K. V., \& Taylor, P. W. (2012). Cost of reproduction in the Queensland fruit fly: Y-model versus lethal protein hypothesis. Proceedings of the Royal Society B: Biological Sciences, 279(1749), 4893-4900. https://doi.org/10.1098/rspb.2012.2033

Geer, B. W., Heinstra, P. W. H., \& McKechnie, S. W. (1993). The biological basis of ethanol tolerance in Drosophila. Comparative Biochemistry and Physiology -- Part B: Biochemistry And, 105(2), 203-229. https://doi.org/10.1016/0305-0491(93)90221-P

Grandison, R. C., Piper, M. D. W., \& Partridge, L. (2009). Amino-acid imbalance explains extension of lifespan by dietary restriction in Drosophila. Nature, 462(7276), 10611064. https://doi.org/10.1038/nature08619

Harrison, D. E., Strong, R., Sharp, Z. D., Nelson, J. F., Astle, C. M., Flurkey, K., ... Miller, R. A. (2009). Rapamycin fed late in life extends lifespan in genetically heterogeneous mice. Nature, 460(7253), 392-395. https://doi.org/10.1038/nature08221

Imafidon, G. I., \& Sosulski, F. W. (1990). Nucleic Acid Nitrogen of Animal and Plant Foods. Journal of Agricultural and Food Chemistry, 38(1), 118-120. https://doi.org/10.1021/jf00091a024

Kapahi, P., Kaeberlein, M., \& Hansen, M. (2017). Dietary restriction and lifespan: Lessons from invertebrate models. Ageing Research Reviews, 39, 3-14. https://doi.org/10.1016/j.arr.2016.12.005 
737

Katewa, S. D., Akagi, K., Bose, N., Rakshit, K., Camarella, T., Zheng, X., ... Kapahi, P. (2016). Peripheral Circadian Clocks Mediate Dietary Restriction-Dependent Changes in Lifespan and Fat Metabolism in Drosophila. Cell Metabolism, 23(1), 143-154. https://doi.org/10.1016/j.cmet.2015.10.014

Kirkwood, T. B. L. (1977). Evolution of ageing. Nature, 270, 301-304.

$$
\text { https://doi.org/10.1038/270301a0 }
$$

Kirkwood, T. B. L., \& Rose, M. R. (1991). Evolution of senescence: late survival sacrificed for reproduction. Philosophical Transactions - Royal Society of London, B, 332(1262), 1524. https://doi.org/10.1098/rstb.1991.0028

Le Couteur, D. G., Solon-Biet, S., Cogger, V. C., Mitchell, S. J., Senior, A., De Cabo, R., ... Simpson, S. J. (2016). The impact of low-protein high-carbohydrate diets on aging and lifespan. Cellular and Molecular Life Sciences, 73(6), 1237-1252. https://doi.org/10.1007/s00018-015-2120-y

Lee, K. P., Simpson, S. J., Clissold, F. J., Brooks, R., Ballard, J. W. O., Taylor, P. W., ... Raubenheimer, D. (2008). Lifespan and reproduction in Drosophila: New insights from nutritional geometry. Proceedings of the National Academy of Sciences of the United States of America, 105(7), 2498-2503. https://doi.org/10.1073/pnas.0710787105

Leitão-Gonçalves, R., Carvalho-Santos, Z., Francisco, A. P., Fioreze, G. T., Anjos, M., Baltazar, C., ... Ribeiro, C. (2017). Commensal bacteria and essential amino acids control food choice behavior and reproduction. PLoS Biology, 15(4), 1-29. https://doi.org/10.1371/journal.pbio.2000862

Lesperance, Danielle N.A., Broderick, N. A. (2020). Meta-analysis of Diets Used in Drosophila Microbiome Research and Introduction of the Drosophila Dietary Composition Calculator (DDCC). G3 (Bethesda, Md.), 10(7), 2207-2211. https://doi.org/10.1534/g3.120.401235

Lin, S.-J., Kaeberlein, M., Andalis, A. A., Sturtz, L. A., Defossez, P.-A., Culotta, V. C., ... Guarente, L. (2002). Calorie restriction extends Saccharomyces cerevisiae lifespan by increasing respiration. Nature, 418(6895), 344-348. https://doi.org/10.1038/nature00829 
766

Linford, N. J., Bilgir, C., Ro, J., \& Pletcher, S. D. (2013). Measurement of lifespan in Drosophila melanogaster. Journal of Visualized Experiments, (71), 1-9.

$$
\text { https://doi.org/10.3791/50068 }
$$

Liu, G. Y., \& Sabatini, D. M. (2020). mTOR at the nexus of nutrition, growth, ageing and disease. Nature Reviews Molecular Cell Biology, 21(4), 183-203. https://doi.org/10.1038/s41580-019-0199-y

López-otín, C., Blasco, M. A., Partridge, L., Serrano, M., \& Kroemer, G. (2013). The Hallmarks of Aging Longevity. Cell, 153(6), 1194-1217. https://doi.org/10.1016/j.cell.2013.05.039.The

Ma, C., Mirth, C. K., Hall, M. D., \& Piper, M. D. W. (2020). Amino acid quality modifies the quantitative availability of protein for reproduction in Drosophila melanogaster. Journal of Insect Physiology, 104050. https://doi.org/10.1016/j.jinsphys.2020.104050

Magwere, T., Chapman, T., \& Partridge, L. (2004). Sex Differences in the Effect of Dietary Restriction on Life Span and Mortality Rates in Female and Male Drosophila Melanogaster. The Journals of Gerontology Series A: Biological Sciences and Medical Sciences, 59(1), B3-B9. https://doi.org/10.1093/gerona/59.1.b3

Mair, W., Piper, M. D. W., \& Partridge, L. (2005). Calories do not explain extension of life span by dietary restriction in Drosophila. PLoS Biology, 3(7), 1305-1311. https://doi.org/10.1371/journal.pbio.0030223

Markow, T. A. N. N., Christiane, N., \& Eric, F. (2015). The secret lives of Drosophila flies. 1-9. https://doi.org/10.7554/eLife.06793

Masoro, E. J. (2005). Overview of caloric restriction and ageing. Mechanisms of Ageing and Development, 126(9 SPEC. ISS.), 913-922. https://doi.org/10.1016/j.mad.2005.03.012

McCay, C. M., Crowell, M. F., \& Maynard, L. A. (1935). The Effect of Retarded Growth Upon the Length of Life Span and Upon the Ultimate Body Size. The Journal of Nutrition, 10(1), 63-79. https://doi.org/10.1093/jn/10.1.63

Min, K. J., \& Tatar, M. (2006). Restriction of amino acids extends lifespan in Drosophila melanogaster. Mechanisms of Ageing and Development, 127(7), 643-646. https://doi.org/10.1016/j.mad.2006.02.005 
795

796

797

798

799

800

801

802

803

804

805

806

807

808

809

810

811

812

813

814

815

816

817

818

819

820

821

822

823

Mirth, C. K., Nogueira Alves, A., \& Piper, M. D. (2019). Turning food into eggs: insights from nutritional biology and developmental physiology of Drosophila. Current Opinion in Insect Science, 31, 49-57. https://doi.org/10.1016/j.cois.2018.08.006

Moatt, J. P., Savola, E., Regan, J. C., Nussey, D. H., \& Walling, C. A. (2020). Lifespan Extension Via Dietary Restriction: Time to Reconsider the Evolutionary Mechanisms? BioEssays, 13. https://doi.org/10.1002/bies.201900241

Münch, D., Ezra-Nevo, G., Francisco, A. P., Tastekin, I., \& Ribeiro, C. (2020). Nutrient homeostasis - translating internal states to behavior. Current Opinion in Neurobiology, 60, 67-75. https://doi.org/10.1016/j.conb.2019.10.004

Partridge, L., Alic, N., Bjedov, I., \& Piper, M. D. W. (2011). Ageing in Drosophila: The role of the insulin/Igf and TOR signalling network. Experimental Gerontology, 46(5), 376-381. https://doi.org/10.1016/j.exger.2010.09.003

Pearl, R., \& Parker, S. L. (1921). Experimental Studies on the Duration of Life . I . Introductory Discussion of the Duration of Life in Drosophila Published by: The University of Chicago Press for The American Society of Naturalists Stable URL : http://www.jstor.com/stable/2456562. 55(641), 481-509.

Piper, M. D. (2017). Using artificial diets to understand the nutritional physiology of Drosophila melanogaster. Current Opinion in Insect Science, 23, 104-111. https://doi.org/10.1016/j.cois.2017.07.014

Piper, M. D. W., Blanc, E., Leitão-Gonçalves, R., Yang, M., He, X., Linford, N. J., Partridge, L. (2014). A holidic medium for Drosophila melanogaster. Nature Methods, 11(1), 100105. https://doi.org/10.1038/nmeth.2731

Piper, M. D. W., \& Partridge, L. (2016). Protocols to study aging in drosophila. Methods in Molecular Biology, 1478, 291-302. https://doi.org/10.1007/978-1-4939-6371-3_18

Piper, M. D. W., Partridge, L., Raubenheimer, D., \& Simpson, S. J. (2011). Dietary restriction and aging: A unifying perspective. Cell Metabolism, 14(2), 154-160. https://doi.org/10.1016/j.cmet.2011.06.013

Piper, M. D. W., Soultoukis, G. A., Blanc, E., Mesaros, A., Herbert, S. L., Juricic, P., ... Partridge, L. (2017). Matching Dietary Amino Acid Balance to the In Silico-Translated 
Exome Optimizes Growth and Reproduction without Cost to Lifespan. Cell Metabolism, 25(3), 610-621. https://doi.org/10.1016/j.cmet.2017.02.005

Raubenheimer, D., \& Simpson, S. J. (2009). Nutritional PharmEcology: Doses, nutrients, toxins, and medicines. Integrative and Comparative Biology, 49(3), 329-337. https://doi.org/10.1093/icb/icp050

Regan, J. C., Froy, H., Walling, C. A., Moatt, J. P., \& Nussey, D. H. (2020). Dietary restriction and insulin-like signalling pathways as adaptive plasticity: A synthesis and reevaluation. Functional Ecology, 34(1), 107-128. https://doi.org/10.1111/13652435.13418

Regan, J. C., Khericha, M., Dobson, A. J., Bolukbasi, E., Rattanavirotkul, N., \& Partridge, L. (2016). Sex difference in pathology of the ageing gut mediates the greater response of female lifespan to dietary restriction. 1-16. https://doi.org/10.7554/eLife.10956

Rera, M., Azizi, M. J., \& Walker, D. W. (2013). Organ-specific mediation of lifespan extension: More than a gut feeling? Ageing Research Reviews, 12(1), 436-444. https://doi.org/10.1016/j.arr.2012.05.003

Ribeiro, C., \& Dickson, B. J. (2010). Sex peptide receptor and neuronal TOR/S6K signaling modulate nutrient balancing in Drosophila. Current Biology, 20(11), 1000-1005. https://doi.org/10.1016/j.cub.2010.03.061

Sabatini, D. M. (2017). Twenty-five years of mTOR: Uncovering the link from nutrients to growth. Proceedings of the National Academy of Sciences of the United States of America, 114(45), 11818-11825. https://doi.org/10.1073/pnas.1716173114 decreases mitochondrial oxygen radical production and oxidative DNA damage in rat liver. Journal of Bioenergetics and Biomembranes, 36(6), 545-552. https://doi.org/10.1007/s10863-004-9001-7 modulates tissue aging and lifespan independently of the gut microbiota in Drosophila.

852 Scialò, F., Sriram, A., Naudí, A., Ayala, V., Jové, M., Pamplona, R., \& Sanz, A. (2015). Target of 
853

854

855

856

857

858

859

860

861

862

863

864

865

866

867

868

869

870

871

872

873

874

875

876

877

878

879

880

881

rapamycin activation predicts lifespan in fruit flies. Cell Cycle, 14(18), 2949-2958. https://doi.org/10.1080/15384101.2015.1071745

Shanley, D. P., \& Kirkwood, T. B. L. (2000). Calorie restriction and aging: A life-history analysis. Evolution, 54(3), 740-750. https://doi.org/10.1111/j.00143820.2000.tb00076.x

Simpson, SJ, Raubenheimer, D. (2012). The Nature of Nutrition : A Unifying Framework from Animal Adaptation to Human Obesity. Princeton University Press, Princeton.

Simpson, S. J., \& Raubenheimer, D. (1993). A multi-level analysis of feeding behaviour: The geometry of nutritional decisions. Philosophical Transactions of the Royal Society B: Biological Sciences, 342(1302), 381-402. https://doi.org/10.1098/rstb.1993.0166

Simpson, Stephen J., Le Couteur, D. G., Raubenheimer, D., Solon-Biet, S. M., Cooney, G. J., Cogger, V. C., \& Fontana, L. (2017). Dietary protein, aging and nutritional geometry. Ageing Research Reviews, 39, 78-86. https://doi.org/10.1016/j.arr.2017.03.001

Simpson, Stephen J., \& Raubenheimer, D. (2009). Macronutrient balance and lifespan. Aging, 1(10), 875-880. https://doi.org/10.18632/aging.100098

Skorupa, D. A., Dervisefendic, A., Zwiener, J., \& Pletcher, S. D. (2008). Dietary composition specifies consumption, obesity, and lifespan in Drosophila melanogaster. Aging Cell, 7(4), 478-490. https://doi.org/10.1111/j.1474-9726.2008.00400.x

Solon-Biet, S. M., McMahon, A. C., Ballard, J. W. O., Ruohonen, K., Wu, L. E., Cogger, V. C., ... Simpson, S. J. (2014). The ratio of macronutrients, not caloric intake, dictates cardiometabolic health, aging, and longevity in ad libitum-fed mice. Cell Metabolism, 19(3), 418-430. https://doi.org/10.1016/j.cmet.2014.02.009

Solon-Biet, S. M., Walters, K. A., Simanainen, U. K., McMahon, A. C., Ruohonen, K., Ballard, J. W. O., ... Simpson, S. J. (2015). Macronutrient balance, reproductive function, and lifespan in aging mice. In Proceedings of the National Academy of Sciences 112 (11) 3481-3486. https://doi.org/10.1073/pnas.1422041112

Southgate, D. A. T., \& Durnin, J. V. G. A. (1970). Calorie conversion factors. An experimental reassessment of the factors used in the calculation of the energy value of human diets. British Journal of Nutrition, 24(2), 517-535. https://doi.org/10.1079/bjn19700050 
882

883

884

885

886

887

888

889

890

891

892

893

894

895

896

897

898

899

900

901

902

903

904

905

906

907

908

909

910

Speakman, J. R. (2020). Why does caloric restriction increase life and healthspan? The 'clean cupboards' hypothesis. National Science Review, 7 (7), 1153-1156.

$$
\text { https://doi.org/10.1093/nsr/nwaa078 }
$$

Starr, P. R., \& Parks, L. W. (1962). Some factors affecting sterol formation in Saccharomyces cerevisiae. Journal of bacteriology, 83(5), 1042-1046.

$$
\text { https://doi.org/10.1128/JB.83.5.1042-1046.1962 }
$$

Taylor, R. C., \& Dillin, A. (2011). Aging as an event of proteostasis collapse. Cold Spring Harbor Perspectives in Biology, 3(5), 1-17.

https://doi.org/10.1101/cshperspect.a004440

Vargas, M. A., Luo, N., Yamaguchi, A., \& Kapahi, P. (2010). A role for S6 kinase and serotonin in postmating dietary switch and balance of nutrients in D. melanogaster. Current Biology, 20(11), 1006-1011. https://doi.org/10.1016/j.cub.2010.04.009

Waithe, D., Rennert, P., Brostow, G., \& Piper, M. D. W. (2015). QuantiFly: Robust trainable software for automated Drosophila egg counting. PLOS ONE, 10(5), 1-16.

https://doi.org/10.1371/journal.pone.0127659

Walker, Samuel J., Goldschmidt, D., \& Ribeiro, C. (2017). Craving for the future: the brain as a nutritional prediction system. Current Opinion in Insect Science, 23, 96-103.

https://doi.org/10.1016/j.cois.2017.07.013

Walker, Samuel James, Corrales-Carvajal, V. M., \& Ribeiro, C. (2015). Postmating Circuitry Modulates Salt Taste Processing to Increase Reproductive Output in Drosophila. Current Biology, 25(20), 2621-2630. https://doi.org/10.1016/j.cub.2015.08.043

Wilson, K., \& McLeod, B. J. (1976). The influence of conditions of growth on the endogenous metabolism of Saccharomyces cerevisiae: effect on protein, carbohydrate, sterol and fatty acid content and on viability. Antonie van Leeuwenhoek, 42(4), 397-410.

https://doi.org/10.1007/BF00410171

Wu, Q., Yu, G., Cheng, X., Gao, Y., Fan, X., Yang, D., ... Yang, M. (2020). Sexual dimorphism in the nutritional requirement for adult lifespan in Drosophila melanogaster. Aging Cell, 19(3), 1-8. https://doi.org/10.1111/acel.13120 